\title{
La lectura simbolista de la obra de Cézanne: la paradoja del modelo
}

\section{The symbolist reading of Cézanne's ouvre: the paradox of the model}

\author{
María Elena Muñoz Méndez \\ Departamento de Teoría de las Artes, Universidad de Chile. Santiago, Chile. \\ malena2265@gmail.com
}

\section{Resumen}

El texto que sigue es fruto de una investigación orientada a explorar los fundamentos de aquel relato que puso a Paul Cézanne en el lugar de iniciador de la pintura moderna. Lo que aquí se propone es que tal instalación paradigmática ocurrió gracias a la proyección de las ideas simbolistas en las interpretaciones tempranas de la pintura del pintor provenzal. En otras palabras, fue el discurso de origen simbolista el que atribuyó a Cézanne la paternidad de la modernidad pictórica cuando aplicó a su pintura unos ciertos criterios de comprensión afines al ideario simbolista, aun cuando estos diferían sustancialmente de las premisas defendidas por el propio Cézanne. De ese modo se explica cómo un pintor que siempre defendió el modelo de la naturaleza aparezca encabezando un tipo de pintura que terminará caracterizándose por su desapego del modelo natural.

Palabras clave: modelo, naturaleza, simbolismo, sensación, realización.

\begin{abstract}
This text is the result of a research oriented to search the foundations in which the idea of Paul Cezanne as founder of modern painting was rooted. We propose that the position granted to Cezanne was the work of a projection made by symbolist critics that articulated the early interpretations of Cezanne's ouvre. In others words, it can be said that the symbolist discourse the one that attributed the paternity of modern painting to the provenzal painter by means of applying certain symbolist's ideas to his painting, although these were substantially different from those that Cezanne himself defended. This way, it is possible to explain how a painter that defended the importance of the natural model was put in an inaugural place of a kind of painting characterized as detached from the model of nature.
\end{abstract}

Keywords: Model, Nature, Symbolism, Sensation, Realization. 
Triunfo universal de la imaginación de los estetas sobre los esfuerzos de la tonta imitación, triunfo de la emoción de lo bello sobre la mentira naturalista.

M. Denis, Homenaje a Cézanne

La pintura de Denis, Homeaje a Cézanne, representa una escena ambientada en la galería de Ambroise Vollard, donde se encuentran reunidos Odilon Redon, Edouard Vuillard, Pierre Bonnard, Paul Sèrusier, Paul Ranson, el propio Denis, su mujer y Vollard, entre otros. La naturaleza muerta de Cézanne que admiran en el atril es Frutero, copa y manzanas de 1880, la que había pertenecido a Paul Gauguin. Este último aparece indirectamente representado por un cuadro suyo en el fondo (al lado de uno de Renoir).

La pintura de Denis ofrece una imagen condensada de la importancia atribuida a la pintura de Cézanne por el círculo de pintores ligados al simbolismo. Tributan su inapelable admiración por el pintor que ellos consideraban les había abierto un fructífero porvenir, el camino para la superación de la "mentira naturalista". La escena ocurre, significativamente, en la galería de Ambroise Vollard, quien fue el primero en organizar una exposición individual del pintor provenzal. El cuadro de Cézanne en el atril había pertenecido a Paul Gauguin, y a través de su intermedio es que el maestro de Aix fue conocido por sus jóvenes amigos y seguidores. Gauguin fue, de hecho, responsable de la admiración que la nueva generación sentía por Cézanne, así como también del sesgo que se impuso sobre su lectura.

\section{La puesta en marcha}

El mundo artístico empezó a reparar seria y sostenidamente en la obra de Cézanne a partir de la exposición organizada en 1895 por Ambroise Vollard (1868-1939). Para esa fecha, hacía casi veinte años que Cézanne no exponía con el grupo de los impresionistas, de los que se encontraba prácticamente desligado, y su participación en algunas muestras colectivas no alcanzó a ser significativa. En efecto, el único lugar donde se podían apreciar algunos de sus trabajos era en la tienda de Père Tanguy, la que era frecuentada por iniciados en el ámbito de la pintura más experimental. Entre los asiduos a dicho lugar se encontraban Denis, Bonnard, Vuillard y Bernard, para quienes la figura del solitario de Aix constituía por esos años un misterio altamente seductor. A la muerte de Tanguy, en 1894, la galería de Vollard asumió la tarea de difundir la obra de los pintores albergados por el viejo marchand. Convencido por Vollard, Cézanne le cedió ciento cincuenta pinturas para que fueran exhibidas en la galería de la calle Lafitte. Se podría decir que el evento de la galería Vollard fue lo que puso en marcha la tradición Cézanne. 
FIGURA 1

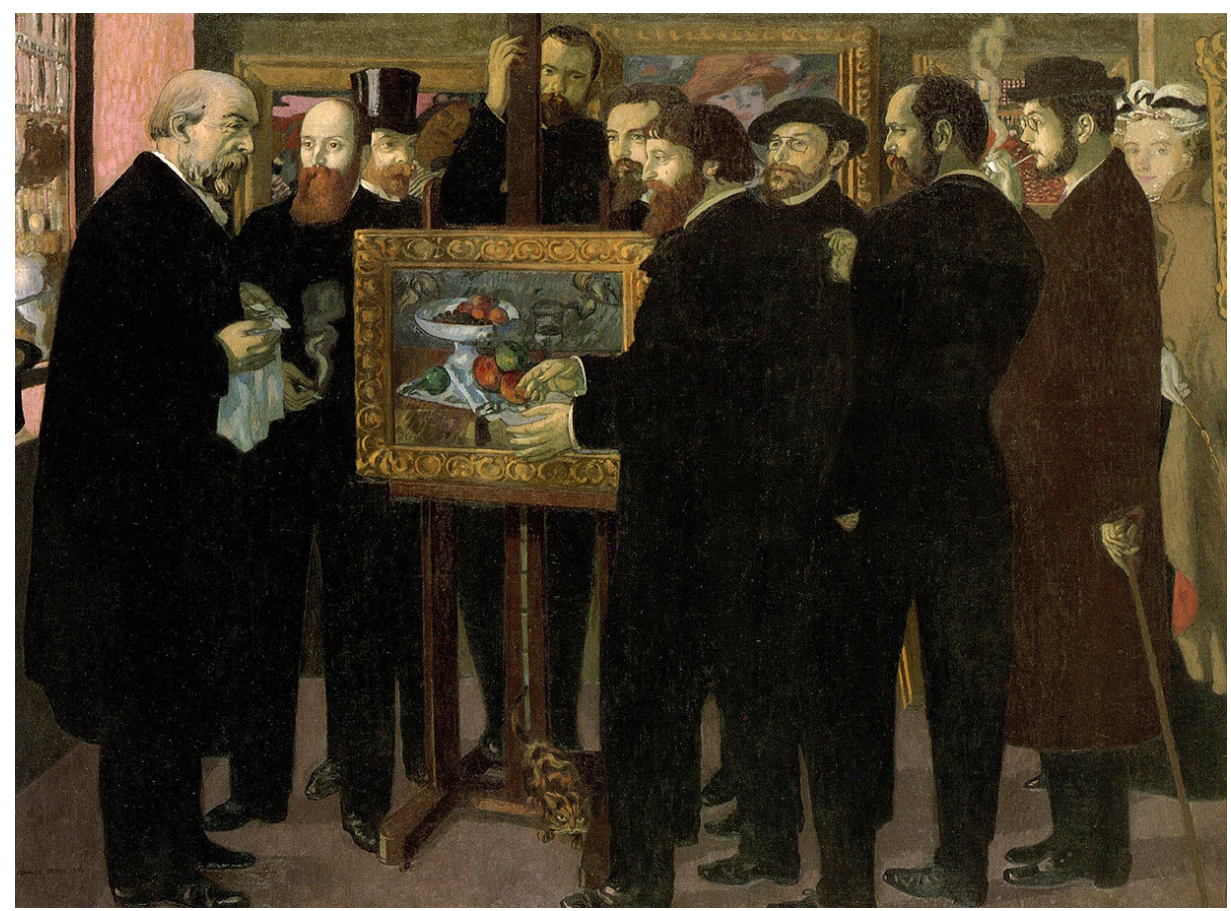

Homenaje a Cézanne (1900), Maurice Denis.

De ahí en adelante, la difusión de su obra se volvió prácticamente imparable. En 1898, otra muestra monográfica se llevó a cabo en la galería de Vollard. Un año más tarde se realizó una subasta de la colección de Victor Choquet, el coleccionista que tempranamente había valorado a Cézanne, donde sus obras alcanzaron precios hasta entonces impensados. Uno de los compradores fue el importante galerista y marchand Durand-Ruel. El mismo año accedió Cézanne a exponer en el Salón de los Independientes y la Exposición Universal de 1900 dio cabida a muchas de sus obras. En 1903, se expusieron algunoss de sus trabajos en la Secesión Vienesa y otros en la de Berlín.

$\mathrm{Al}$ año siguiente, a través de los hermanos Gertrude y Leo Stein, se inicia el interés de los coleccionistas norteamericanos en la pintura de Cézanne. En junio, Émile Bernard -aquel pintor que a juicio de Rilke era "un pintor que escribía, un pintor por tanto que no era tal” (57)- publicó un artículo sobre Cézanne en la revista L' Occident. Tres años después, en octubre de 1907, Bernard publicó otro en el Mercure de France titulado "Souvenirs sur Paul Cézanne". En tanto, en 1905, el mismo periódico publicó una encuesta elaborada por el crítico Charles Morice que reveló su creciente influencia entre jóvenes pintores. En el Salón de Otoño de 1905, Maurice Denis hizo una reseña de su obra señalando que el pintor era el Poussin de las naturalezas muertas y los paisajes campestres. El año de su muerte, 1906, el Salón de Otoño le 
dedicó una sección especial. Un año más tarde, tuvo lugar una gran retrospectiva. Ese mismo año, 1907, fue publicado el artículo de Riviére y Schnerb en La Grande Revue y Maurice Denis publicó el primero de sus ensayos sobre el pintor. En 1908 se realizó en Moscú una exposición de impresionismo y (neo)impresionismo. El ensayo de Denis fue traducido al inglés por el pintor y crítico británico Roger Fry y publicado en el Burlington Magazine en 1910, lo cual ayudó a divulgar la obra cezanniana entre los artistas y el público anglosajón.

Ese mismo año, Fry acuñó el término "postimpresionistas" con ocasión de la muestra "Manet y los postimpresionistas", que él mismo organizó y que tuvo lugar en las Grafton Galleries en Londres. El término lo usó para referirse a la obra de Gauguin, Van Gogh y Cézanne, a quienes veía unidos por un común rechazo a lo que interpretaba como la actitud pasiva del impresionismo hacia la apariencia de las cosas. El propósito de Fry era enfrentar al público londinense con el arte francés al que percibía como más pleno y definitivamente más predispuesto a la modernidad que el inglés. Ese mismo año, acompañando a la muestra, Fry publicó sendos artículos sobre el nuevo arte que veía la luz en Londres, donde sindicaba a Cézanne como un gran genio, el verdadero iniciador del "movimiento" más prometedor y fructífero de los tiempos modernos. A principios de 1911, Alfred Stieglitz exhibió en su galería neoyorquina una serie de dibujos y litografías del maestro de Aix, y hacia fines de ese mismo año, el Metropolitan Museum ofreció una muestra de sus acuarelas. En 1912, Fry repitió la experiencia con la segunda exposición postimpresionista, en que el campo de expositores se expandió considerablemente. En 1914, Vollard publicó una monografía sobre Cézanne, mientras que Clive Bell, crítico y pintor inglés muy cercano a Fry, publicó un libro cuyo sintético y acaso pretensioso título era Art. En él, afirmaba: "Tanto como un hombre puede inspirar una época entera, Cézanne inspiró el movimiento contemporáneo [...] Cézanne es el Cristóbal Colón de un nuevo continente de forma [...]. El período en que nos encontramos, en el año 1913, comienza con la madurez de Cézanne" (Bell 32, traducción propia). Años más tarde, el mismo crítico publicó una colección de ensayos titulados Since Cézanne, en un intento por delimitar el desarrollo del arte visual moderno como consecuencia de la investigación cezanniana.

Estos son solo algunos de los eventos que pusieron en marcha la institución Cézanne en la historia del arte moderno. Desde entonces, se difundió la estampa ejemplar de este solitario, enemigo del bullicio, que aborrecía a París y al mundo moderno, que repudiaba los ferrocarriles y las ampolletas, como el fundador de la modernidad artística. Como es dable pensar, más que la obra y los principios defendidos por el artista, lo que llevó a configurar la posición paradigmática de Cézanne fue el conjunto de lecturas e interpretaciones de su obra y de sus intenciones por parte de la generación que lo siguió.

La generación que siguió a Cézanne se hizo cargo de asimilarlo a sus propios principios artísticos. Fue la responsable de la divulgación de su figura como la del 
iluminado que los hacía retornar finalmente a los valores universales de lo clásico, pero cuyo mérito fundamental residía en que lo hacía de una manera totalmente nueva, original, que no debía nada a los modelos gastados de la tradición. Al definirlo como defensor de valores universales, se estaba instalando la imagen de Cézanne como el gran superador del impresionismo. Esta lectura canónica tuvo su origen en los artistas/ críticos franceses que interpretaron su obra desde una perspectiva simbolista; luego, fue transformada en lectura formalista al interior del ámbito crítico anglosajón por los ya mencionados británicos Roger Fry, Clive Bell y, más tarde, también por Herbert Read, para finalmente apropiársela la crítica formalista norteamericana, representada fundamentalmente por Clement Greenberg. Las interpretaciones del trabajo de Cézanne tendieron, en líneas generales, a ubicarlo en la línea de lo que podríamos llamar aspiraciones modernas de universalidad, animadas por el deseo de instituirlo como un clásico moderno, de posicionarlo como "el primitivo de una nueva era". A continuación, trataré de esbozar el curso de las líneas interpretativas que generaron la imagen de Cézanne como el padre de la modernidad pictórica, la que, como ya dije, encuentra su origen en los testimonios e interpretaciones dejados por aquellos jóvenes artistas, pintores y poetas que tuvieron la oportunidad de conocerlo durante los años finales de su vida.

\section{La mirada simbolista}

Hacia 1890, el simbolismo era la posición de avanzada en la teoría estética francesa: abogaba por la autonomía del lenguaje y por la exaltación de la experiencia estética. Representaba la alternativa que podía redimir a la poesía y a la pintura del falso naturalismo. En poesía, el simbolismo se reconocía heredero directo de Baudelaire por su apología a la imaginación y por su voluntad de desterrar a la naturaleza como referente de la producción pictórica y poética, alejándose así de toda visión positivista respecto del arte y de la cultura. Especialmente importante para el desarrollo del arte y la teoría simbolista es la noción de correspondencia, anunciada por Baudelaire en su célebre soneto "Correspondances", de Fleurs du Mal (1859). Las correspondencias operan en tres niveles: el primero dice relación con las equivalencias entre los distintos datos sensibles: olores, colores, sonidos, lo que normalmente se refiere con el concepto de sinestesia; el segundo, por su parte, alude a las equivalencias entre imágenes e ideas, deseos, pensamientos, en otras palabras, el "espíritu"; por último, el tercer nivel opera en la relación entre las cosas del mundo y un universo suprasensible, el que proviene de una filosofía mística representada por el filósofo y teósofo sueco Emanuel Swedenborg (1688-1772). Las correspondencias horizontales (entre las cosas del mundo), de las que hablaba Baudelaire, con las correspondencias verticales (entre el cielo y la tierra), de las que hablaba Swedenborg, se fundieron luego en el ideario simbolista. 
No obstante, más allá de las correspondencias, el simbolismo debe a Baudelaire una idea central: el abandono de la naturaleza como referente de la creación. Así, el simbolismo venía a entenderse como lo opuesto al principio de imitación. La naturaleza pierde su lugar como referente y ello da lugar a la producción de una poesía libre, evocativa de aquello que los sentidos no pueden captar por sí solos. Sin embargo, Baudelaire y las otras grandes figuras del simbolismo, como Mallarmé o Verlaine, no se pueden identificar linealmente con aquello que iba a ser definido como tal por el poeta Jean Moréas, aunque no pudieron evitar ser sindicados como figuras modélicas. Si bien es cierto que estos poetas fundamentales figuraban como precursores, Mallarmé y Verlaine (Baudelaire ya muerto) no se sintieron nunca parte del entusiasmo redentor de los jóvenes simbolistas ni del declarado misticismo de algunos de ellos. El simbolismo -como "movimiento"- había surgido hacia fines de la década del ochenta al interior de un círculo de poetas y escritores que buscaban alejarse de los motivos temáticos dominantes y que postulaban la necesidad de crear un lenguaje depurado, en el que la acción de las palabras no estuviese sujeta a la descripción de los hechos y de las cosas del mundo. Subrayaban que la nueva poesía debía evocar "ideas inmateriales mediante una desviación (o deformación) de la visión objetiva de los naturalistas”. El poeta Jean Moréas (pseudónimo de Giannis Papadiamantopoulos) publicó en septiembre de 1886, en el diario Le Figaro, el "Manifiesto simbolista". Allí se puede leer lo siguiente:

La poesía simbólica [sic] busca vestir a la Idea de una forma sensible que, sin embargo no sería su objetivo, pero que al servir para expresar la Idea, permanecería sujeta. La Idea, a su vez, no debe dejarse ver en absoluto privada de las suntuosas analogías exteriores; porque el carácter esencial del arte simbólico consiste en no ir jamás hasta la concepción de la Idea en sí misma. Así, en este arte, los cuadros de la naturaleza, las acciones de los humanos, todos los fenómenos concretos no sabrían manifestarse por sí mismos: son apariencias sensibles destinadas a representar sus afinidades esotéricas con las Ideas primordiales (cit. en Jenny 29).

La forma sensible era una materialidad que se correspondía con la Idea, a la que solo debía sugerir, sin alcanzarla plenamente; la intención general es representar una afinidad. En el vocabulario del simbolismo, los términos "idea" y "símbolo" eran usados indistintamente y sus sentidos permanecieron en un territorio confuso. Para Moréas, el símbolo constituye el equivalente sensible de la Idea, pero esta Idea podía ser de naturaleza diversa: tanto abstracta como expresiva de un temperamento individual. De cualquier forma, pone énfasis en la supeditación del lenguaje al servicio de la Idea; los signos o símbolos empleados, aun cuando eran comprendidos como equivalencias, parecían a veces detentar un carácter instrumental: no tenían valor por sí mismos.

La mímesis del mundo sensible no tiene lugar en este ideario. Al no estar atada a ella, la palabra queda exonerada de su condición referencial y de su univocidad significativa, con lo que se abre a la equivocidad de nuevos sentidos, por una parte, 
y a las posibilidades de su mera sonoridad (o musicalidad), por otra, y finalmente se consolida como "poesía pura". El lenguaje no denomina; acaso sugiere, evoca. Como había dicho Mallarmé: "Nombrar un objeto supone suprimir tres cuartas partes del placer del poema, que consiste en el deleite de la comprensión gradual. Sugerirlo, ese es el sueño" (Mallarmé, cit. en Bozal 40). Esta liberación de la palabra respecto del mundo sensible no sucede azarosamente ni de manera espontánea, sino que es resultado de una cuidadosa manipulación cuyo modelo, en muchos o en la mayoría de ellos, es la música. En este punto, los simbolistas siguen a Mallarmé. Para Mallarmé, la música no es de modo alguno la expresión de una realidad sensible, sino más bien su aniquilación. El atractivo que ofrece la música radica, más que en sus características anecdóticas, en el principio silencioso que la rige: la "musicalidad". Esta musicalidad es, según el autor, capaz de: "Liberar sin contornear, tanto en el libro como en el texto y fuera de un puñado de polvo o realidad, la dispersión volátil, es decir, el espíritu que no posee otra función aparte de la musicalidad del todo" (cit. en Jenny 77).

La musicalidad tiene la propiedad de liberar al espíritu, de evocar una resonancia de armonía universal sin necesidad de atarse al mundo por algún tipo de mecanismo referencial. El rol ejemplar de la música constituyó una de las premisas del simbolismo tanto poético como pictórico. Al respecto, Paul Valéry expresó: "lo que fue bautizado con el nombre de simbolismo se resume harto sencillamente en la intención, común a diversas familias de poetas (por otra parte enemigas entre sí) de recuperar de la Música, algo que siempre les perteneció" (Todó 116). La música no describe, no traduce, no replica el mundo de las cosas y los seres; su eficiencia depende de su organización interna, de las armonías que se modulan (tal como quería Cézanne hacer con los colores) para provocar un efecto.

\section{Platón, el simbolismo y la pintura}

El simbolismo, en su fase más militante, era también llamado "ideísmo". Se distinguía así tanto del ciego naturalismo como del idealismo, ya que en lugar del ideal afirmaba la primacía de la Idea. La teoría platónica de las ideas fue invocada para defender el destino superior del arte y del artista como exponente o traductor de la verdad y no como mero reproductor del mundo físico. Los argumentos platónicos que han servido para condenar a las artes imitativas son los expresados específicamente en los libros III y x de La República, texto fundamental de su pensamiento maduro. Dicha reflexión se enmarca dentro de la configuración de un modelo de sociedad, y un pensamiento sobre la vida social no puede dejar de lado la modelación de las representaciones. La actividad mimética se hace acreedora de su rechazo porque parece estar concentrada nada más que en la producción de fantasmas, de simulacros y de engaños; es decir, permanece alejada de la verdad y por ende, del bien. Puesto que poetas y pintores, que en realidad no tienen conocimiento sobre las cosas reales ni 
su funcionamiento -como sí lo pudiera tener un zapatero o un herrero- se limitan solamente a replicar el aspecto de las cosas, esto es, su apariencia, entonces sus obras, precisamente en cuanto miméticas (producción de phantasmata), se presentan como aquello que señala, que hace nítida y distintiva la falsedad ( $p s e u d o s$ ). De este modo, la mímesis traería a presencia aquello que puede definirse como lo opuesto a la verdad; el engaño al que nuestros sentidos nos exponen en el mundo fenoménico. El arte imitativo está lejos de lo verdadero cuando representa las semblanzas en lugar de las ideas, la apariencia sensible en lugar de la realidad, realidad que, en cuanto idea, no puede sino ser inteligible.

Amparado en la doctrina platónica y en otras fuentes que se funden en el pensamiento simbolista, el poeta y crítico Albert Aurier propone liberar al artista de la función mimética, para colocarlo en la suprema función de dar a conocer una verdad que, en principio, solo para él es visible. A su modo de ver, el arte ideístico representaba la salvación para el arte, especialmente para la pintura. La pintura, de acuerdo a Aurier, estaba sumida en una especie de pozo de la que por siglos le había costado salir, anclada a su nefasto apego por la producción de pseudos. Platón es invocado persistentemente para avalar el tipo de arte al que está llamando el ideísta, un arte que ha roto las cadenas que lo ataban - por desconocimiento o por estupidez- al ejercicio de la mímesis de lo sensible. En un párrafo que en realidad evidencia su poca familiaridad con la historia de la pintura, Aurier proclama:

[...] la tendencia general de la pintura ha sido hasta ahora, como todo el mundo sabe, casi exclusivamente realista [...] Incluso los propios idealistas (que, repito, no deben ser confundidos con los artistas que quiero llamar ideístas) no han sido casi siempre sino realistas, aunque pretendan no serlo; su propósito no ha sido otro que la representación directa de las formas materiales [...] Son también pobres y estúpidos prisioneros de la alegórica caverna. Dejemos que se engañen a sí mismos mirando las sombras que ellos piensan es la realidad, y volvamos a quienes, rotas sus cadenas y lejos de su cruel prisión en que nacieron, contemplan extasiados el cielo radiante de las Ideas. El normal y último propósito de la pintura, como del resto de las artes, nunca puede ser la representación directa de las cosas. Su meta es la expresión de las Ideas, traduciéndolas a un lenguaje especial (Aurier en Chipp 105-6).

El "hombre de genio", el "vocero de los seres absolutos" no tenía que simplemente "fijar" en palabras (signos) las ideas ni expresarlas de manera unívoca y directa, sino evocarlas a través de equivalencias, sugerirlas, como proponía Mallarmé, "traduciéndolas a un lenguaje especial”, al decir de Aurier. El mundo fenoménico es nada más que un obstáculo necesario de salvar. Al simbolismo le corresponde realizar no la traducción de los objetos que pueblan el mundo, sino la equivalencia sensible de la Idea, expresada mediante su construcción o descubrimiento intuitivo entre colores, formas y contenidos del espíritu. 
La opinión de Albert Aurier estaba también marcada por las ideas baudelerianas, especialmente aquellas relativas al desprecio por la naturaleza como referente de la producción artística, al rechazo de la fotografía y de la pintura que se contenta con la mera reproducción. Es la imaginación la que debe regir la creación del artista y no la naturaleza ni las anécdotas triviales del mundo social. El modelo poético conmina a Aurier a identificar este tipo de pintura con las orientaciones simbolistas de la poesía, que también tomaban distancia de cualquier intención de significar los datos del mundo, del uso referencial del lenguaje. Como había sostenido Mallarmé, no se trataba de pintar la cosa, sino el efecto que produce. El efecto de la cosa o de la acción tenía que ser, como hace siglos postulaba Aristóteles, la meta de la producción de arte; no la reproducción del objeto o de la acción sino la producción de un verosímil capaz de generar un efecto en el espectador.

En ese contexto, la creación artística era percibida como experiencia mística, como sustituto de una religiosidad perdida, y las correspondencias que se apreciaban no eran tan solo las que podían encontrarse entre la forma sensible y el espíritu del artista, sino también aquellas que involucraban los elementos sensibles y el mundo trascendente. La manifestación de esas correspondencias requería del artista una suerte de retiro, que le permitiera rencontrarse con algo así como el espíritu en su pureza. En la mayoría de los casos, ese retiro se hizo efectivo con el desplazamiento de artistas lejos de las urbes; así ocurrió con la comunidad de pintores que operaba en Pont Aven en la década de los ochenta, de la cual participaron entre otros Bernard, Antequin, Sérusier y Gauguin. Fueron los trabajos y las opiniones de este último los que, en principio, movilizaron la teoría de los equivalentes pictóricos que era clave para la "escuela" de Pont Aven. Gauguin no hablaba de significar el mundo, sino de concretar pictóricamente, de transponer las percepciones emotivas (lo que para él eran las sensaciones) que surgen del enfrentamiento con él. Ante todo, Gauguin quería expresar el carácter, expresar la idea interior, hasta la fealdad; incitaba a sus seguidores a utilizar los medios libremente, recurriendo a la exaltación, sobre todo la del color. Para el autor, la pintura era un medio que debía adaptarse a los requerimientos del espíritu; sus cuadros mostraban a los jóvenes pintores que era posible alcanzar una síntesis entre manifestación subjetiva y representación del mundo.

La pintura de Gauguin, particularmente la que realizó durante su estancia en Pont Aven (intermitentemente entre 1888 y 1889), se caracterizaba por una representación simplificada de los volúmenes, la utilización de amplios planos de color sin modelar y el uso de marcados ribetes oscuros. También era referida como pintura "sintética" (teniendo en cuenta nuevamente a Baudelaire, es de suponer), pues revelaba una síntesis entre una deformación objetiva de origen impresionista y una deformación subjetiva de temple simbólico. Efectivamente, eran imágenes pictóricas que deliberadamente se alejaban de las orientaciones supuestamente "positivistas" del impresionismo, para adentrarse en el territorio de aquello a lo que no se accede por los ojos. Se trata de una pintura que daba la espalda a la observación de una realidad 
FIGURA 2

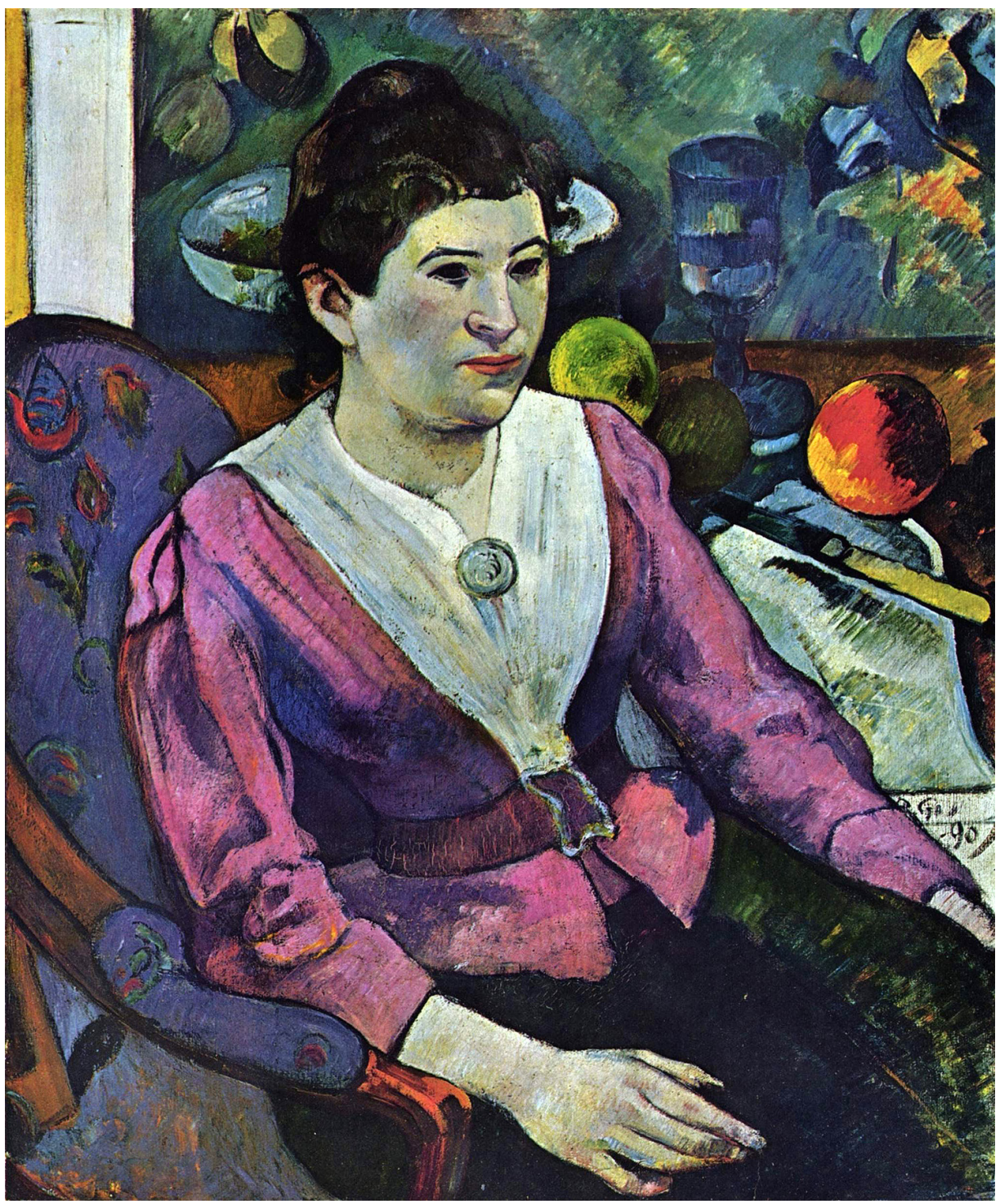

Retrato de Marie Derrien (con naturaleza muerta de Cézanne) (1890), Paul Gauguin.

externa, para privilegiar, a través de un depurado lenguaje de formas visuales, el mundo de las correspondencias simbólicas o de lo que ellos llamaban, más precisamente, las equivalencias. Por la inclinación hacia la expresión de una idea inmaterial en formas visibles y materiales, la pintura sintética o simbolista reveló su estrecha asociación con el simbolismo literario. Esta inclinación era afín a la idea, expresada por Aurier en 1891, de que los pintores simbolistas se comportaban como visionarios que no se 
limitaban a contemplar el despliegue de las apariencias como hacían los impresionistas, sino que expresaban ideas o esencias con los medios a su disposición.

Gauguin se había trasladado a la Bretaña, huyendo de la agitación parisina en busca de un lugar tranquilo que no exhibiera aún los agobiantes rasgos de la modernización; un lugar incontaminado por los vicios del mundo civilizado, donde perviviera un auténtico sentido religioso; un locus de lo "primitivo". Para Gauguin, como para muchos de sus contemporáneos, lo primitivo era la fuerza que se oponía a lo moderno, entendido este último como el proceso de industrialización creciente que experimentaban las sociedades de Europa central en ese entonces. Lo primitivo era sinónimo de pureza moral y se volvió también el lugar de lo místico y de lo universal. Sin embargo, junto con ello, tenía que encontrarse también una fórmula de lo primitivo en el lenguaje expresivo, lo que era representado por el sintetismo pictórico.

A partir de 1888, la pintura de Gauguin se convirtió en una manifestación disidente contra el impresionismo parisino, cuestión que podía reconocerse a simple vista: los colores eran puros, más bien arbitrarios; las formas, simples y ribeteadas. No se percibía atmósfera, y sus motivos no representaban necesariamente aspectos del mundo exterior, como si el apego a lo natural le tuviera sin cuidado. En ese sentido, proponía apartarse en lo posible del modelo de la naturaleza y sugería, en cambio, crear de acuerdo al modelo de la creación divina y el dictado de la imaginación en cuanto orden superior. Gauguin aconsejaba a sus seguidores lo contrario de lo que sugería Cézanne. Para que la pintura alcanzara plenamente los altos objetivos por él anhelados, era preciso que se alejara lo más posible de lo que produce la ilusión de las cosas, marchar en dirección opuesta a la fotografía y a la imagen impresionista del mundo.

En efecto, Gauguin sostenía una crítica frontal a lo que él entendía como la voluntad cientificista del impresionismo. Para Gauguin, el impresionismo constituía un correlato de ese mundo contaminado y de esa mirada positivista de la que quería escapar. Concebía al impresionismo al lado de la civilización. Mientras estaba en Tahití, su ánimo anti-impresionista aumentó. En uno de sus manuscritos, expresa:

\footnotetext{
Los impresionistas estudian el color exclusivamente como un efecto decorativo, pero sin libertad, manteniendo las cadenas de la verosimilitud [...] Sólo prestan atención a la vista, y olvidan los misteriosos centros del pensamiento, cayendo así en un razonamiento meramente científico [...] Es un arte por entero superficial, lleno de afectación y totalmente material... En él no hay pensamiento (cit. en Chipp 81).
}

El impresionismo le parecía demasiado "retiniano". La ideas de Gauguin sobre la pintura -a la que consideraba la más perfecta de las artes- provenían de la poesía simbolista que abogaba por un arte apartado del mundo sensible, pero también alejado del lenguaje de los lugares comunes (escritos o pintados), visto como funcional a los intereses de la burguesía. 
De acuerdo a la teoría de las correspondencias, se había desarrollado una relación muy estrecha entre poesía y pintura. En efecto, existía una vinculación de amistad explícita entre poetas y pintores, una fluida retroalimentación teórica. Varios de los pintores reunidos en Pont Aven compartían una vocación literaria, la que ejercían en la forma de crítica, de poesía o de elaboración escrita de sus propias ideas pictóricas, lo que en definitiva no era extraño en el contexto de una poética que estimaba la expresión de la Idea. De igual forma que los poetas, Gauguin aspiraba a lograr con los colores lo que los músicos lograban con sus armonías. El "antirretinianismo poético" de Gauguin lo animaba a rechazar la presencia del modelo (o del motivo, en estricto rigor) como referente directo de la creación artística. Así, instaba a sus jóvenes amigos a pintar: "La tarea del pintor no es la misma que la del albañil, que, plomada en mano, construye una casa según el plano del arquitecto. Es bueno que los jóvenes tengan un modelo con tal de que lo cubran con una cortina mientras pintan" (cit. en Chipp 81).

Pintar de memoria, cubrir el modelo, como antes había hecho el Sr. G. elogiado por Baudelaire: hacer abstracción de la naturaleza, guiarse por la imaginación y las sensaciones subjetivas. Pintar de memoria ofrecía al artista una libertad inusitada, le permitía realmente ejercer como creador (según el modelo divino). Entre otras cosas, eso era lo que los literatos-pintores y poetas simbolistas instigados por Gauguin tenían en mente antes de llegar a conocer la obra de Cézanne y, posteriormente, su persona.

\section{Cézanne, "místico" y "clasicista"}

La interpretación canónica de Cézanne se desarrolló fundamentalmente a partir de las impresiones que los artistas Émile Bernard (1868-1941) y Maurice Denis (1870-1943) estamparon sobre el artista y sus denodados esfuerzos por conquistar la realización pictórica. Ambos - pertenecientes a la generación posterior a Cézanne y los impresionistas- eran pintores además de críticos establecidos, y siempre mantuvieron claras inclinaciones literarias. Junto con otros artistas y poetas participaron del círculo de los simbolistas, y es en tanto tales que leyeron e interpretaron la obra y las aspiraciones cezanneanas. Su adhesión al simbolismo determinó su apreciación por el trabajo de Cézanne, cuestión que es relevante en la medida en que la lectura que ellos hicieron determinó la inscripción de Cézanne en la historia del arte y, más que eso, la institución de su pintura como modelo de modernidad pictórica. Se trataba de la recepción de un legado que estuvo tamizada por una visión anterior, proveniente, en gran medida, de las derivas de la poesía simbolista.

Bernard tuvo la ocasión de conocerlo personalmente cuando lo visitó en Aix, en enero de 1904. De ahí en adelante, estableció fluidas conversaciones -tanto directas como epistolares- con el maestro, al que reconocía entonces como su único guía. Ese mismo año escribió un conocido estudio "testimonial" sobre el pintor, que se publicó en el periódico L'Occident. Sesgado por sus propias ideas sobre el arte y sus 
convicciones existenciales, así como en sintonía con los principios de la escuela de Pont Aven, donde participó, y con los de la escuela de los Nabís ("profetas", en hebreo), describió a Cézanne como "un místico con inquietudes simbolistas”. En efecto, la propia experiencia de trabar contacto directo con Cézanne fue para Bernard una experiencia mística; se presentó como una revelación, como una oportunidad espiritualmente única de acceso a las lecciones del maestro, un acercamiento a la "verdad" de la pintura. El siguiente párrafo da cuenta de ello:

Cézanne es un místico precisamente gracias a su desdén por el tema, gracias a su carencia de visión natural, a través del gusto que los paisajes, las naturalezas muertas y retratos muestran de manera tan noble y elevada; en resumen, a través de su estilo [...] A través del contacto no con los instintos vulgares que buscan los realistas, sino de la parte contemplativa de nuestro ser, la cual es tocada por la misteriosa influencia de las armonías dispersadas por el mundo, sus pinturas despiertan en nosotros las raras sensaciones que uno puede experimentar del modelo divino. Sólo un místico puede contemplar así la belleza que envuelve al mundo. En lugar de permanecer prisionero de la mera materialidad mundana, sus pinturas nos cuentan que es él, el único que puede ver bien [...] Entre todos los grandes pintores, Paul Cézanne puede ser llamado un místico, porque nos enseña una lección sobre el arte, porque él ve las cosas, no en sí mismas, sino en su vínculo directo con la pintura, o, a través de la concreta expresión de su belleza (Bernard cit. en Doran 40-1).

El "misticismo" que atribuía a Cézanne era una cualidad que le permitía a Bernard colocarlo en la trinchera del simbolismo. Para Bernard, Cézanne era un místico porque sustentaba algo así como una percepción abstracta (no naturalista) de las cosas: veía estética y no objetivamente. Era el prisionero que se había liberado de las cadenas de la caverna. En virtud del rechazo declarado del simbolismo hacia toda forma de naturalismo, Bernard quiso ver a Cézanne como el paradigma que señalaba un camino alternativo, para reafirmar aun más la idea de que el arte no tenía por misión representar el mundo sensible. Según lo que se desprende de algunos de sus escritos, era difícil para Bernard reconocer que un método de pintura tan ordenado y en control como el de Cézanne obedeciera meramente a la observación del natural. Antes bien, prefirió suponer que tanta rigurosidad se hallaba necesariamente comprometida con la creación de una armonía visible universal, correlato de un orden superior, de acuerdo a la creencia en las correspondencias verticales.

Para Bernard, el misticismo iba de la mano con el clasicismo: ambos estaban orientados hacia la armonía universal. Pero a pesar de que la armonía que Cézanne buscaba se relacionaba con la naturaleza, Bernard no le asignó mayor relevancia a esta cuestión. El artículo publicado en L'Occident tiene, como señala Shiff, "una estructura curiosa que pone de manifiesto la diferencia que había entre el concepto que tenía Cézanne de un clasicismo cultivado de carácter natural (es decir, original, espontáneo) 
y el concepto que tenía Bernard de un naturalismo ingenuo de carácter clásico (es decir, sistemático, reflexivo)" (Shiff 174). En respuesta a un borrador del artículo que Bernard envió a Aix, Cézanne tuvo que insistir una vez más en su posición: “Apruebo en buena medida las ideas que va a desarrollar Ud. en su próximo artículo destinado a Occident. Pero yo siempre vuelvo a lo mismo: el pintor debe consagrarse por entero al estudio de la naturaleza y realizar cuadros que sean una enseñanza. Las habladurías sobre el arte son prácticamente inútiles" (Cézanne 374).

A pesar de estas advertencias, Bernard insistió en posicionar a Cézanne, más allá de la naturaleza y del impresionismo, como su superador, en virtud de un misticismo que lo impulsaba a descubrir leyes universales. Por tanto, lo presenta como un artista fundamentalmente reflexivo, exitoso en el descubrimiento de ciertas leyes universales y cuyo triunfo mayor sería la superación de los lastres naturalistas y positivistas del impresionismo. Cézanne se ciñe al modelo natural en un inicio, admite Bernard, pero luego abstrae su pintura hacia un fin más esencial, hacia una pintura no referencial y autosuficiente. A partir de los fenómenos naturales, el pintor habría podido acceder a unas leyes mediante la aplicación de un orden que organiza estos fenómenos percibidos. Refiriéndose a las percepciones cezannianas, el autor afirma: "la lógica, se apodera de ellas [de las percepciones] y realiza su labor por medio de una síntesis imponente y llena de vida" (Bernard, cit. en Doran 61). El proceso cezanniano implicaría entonces dos momentos distintos: un primer momento en que se encuentra con el modelo natural y un segundo momento donde organiza las sensaciones obtenidas en dicho encuentro. No es una lógica de las sensaciones (la lógica de Cézanne) lo que entiende Bernard, sino una lógica que se articula sobre ellas, que se aplica para controlarlas. No resulta difícil notar en esta interpretación los nexos con cierta abstracción futura, especialmente con aquella que concibe a la pintura como la encarnación visible de un racionalismo de tipo místico.

Cézanne le debe al ejercicio au plein air, practicado por la mayoría de los impresionistas, su disposición al modelo y su realización. Sin embargo, sus lectores inmediatos no tuvieron en cuenta una cuestión tan decisiva como esa. Mediante una frase que se le atribuye y que ha sido citada profusamente: "yo he querido hacer del impresionismo algo sólido y durable como el arte de los museos"1, se ha advertido su voluntad de promover una síntesis entre la composición rigurosa de los clásicos y el lenguaje colorístico del impresionismo. Pero la frase en cuestión no está contenida en la correspondencia recopilada y editada por Rewald, y por lo tanto no consta que efectivamente sea suya: lo cierto es que aparece referida en el ensayo sobre Cézanne publicado por Denis en 1907.

Denis, asimismo, fue quien afirmó que Cézanne pretendía convertirse en algo así como "un Poussin del natural, al aire libre, con el color y la luz" (314), pese a que

1 No hay ninguna fuente que demuestre que Cézanne haya dicho esto. 
Cézanne no se refiriera en ninguna de sus cartas al pintor clásico. Un asunto que destaca el historiador norteamericano Theodore Reff para poner en cuestión el papel paradigmático que se le asigna a Poussin en la configuración de la pintura cezanniana es que, revisados sus muchísimos estudios y bocetos después de su muerte, apenas se hallaron tres dibujos correspondientes a copias del maestro del siglo xviI. En realidad, en sus numerosas visitas al Louvre, Cézanne prefirió copiar el trabajo de sus admirados Delacroix y Rubens, además de algunos venecianos y Puget, antes que Poussin. Otra frase que se le atribuye: "Imaginar a Poussin totalmente rehecho desde la naturaleza", tampoco figura en su correspondencia, sino que apareció en una de las crónicas de Bernard. Cézanne, ahora bien, mantenía en su taller una reproducción fotográfica de Los pastores de Arcadia de Poussin, pintura a la que se refería elogiosamente. Pareciera ser que "rehacer a Poussin", si es que así lo dijo el maestro, fue interpretado laxamente como voluntad de orden; lo mismo opinó años después Eugenio D’Ors: "rehacer a Poussin quiere decir una conducción del arte por el camino del orden, de la composición, de la racionalidad" (98). En efecto, el desafío cezanniano estaba comprometido con el deseo de alcanzar la armonía, y ese deseo puede bien interpretarse como clásico, como coinciden muchos estudiosos. Pero para Cézanne, este era un objetivo al que no se podía llegar siguiendo las normas académicas o aplicando un plan racional, como pudiera desprenderse de la frase de D'Ors, sino desde la lección que brinda la naturaleza cuando se está dispuesto a aprenderla.

Cézanne expresó su deseo de volver a un cierto clasicismo al insistir en la relevancia de lo perdurable, al despreciar los devenires de la contingencia. Le perturbaba el aspecto cambiante que las variaciones lumínicas o las transformaciones urbanas imponían sobre la realidad. Esta vocación por lo inmutable, unida al desprecio por lo fugitivo y transitorio, explica su alejamiento del impresionismo y de la urbe, e indica también su voluntad de reconciliar el estudio del natural con las lecciones que ofrece el museo. Pretendía hallar el justo medio: se daba cuenta de que la vía para ser un nuevo clásico no era la recurrencia a ideas preconcebidas o impuestas desde una voluntad idealizadora, sino un camino construido a partir de la organización de las sensaciones que surgen frente a la naturaleza. Del impresionismo adoptó el abandono de las convenciones de taller, la liberación colorística, la disposición frente a la naturaleza para acatar la lección que esta le brinda. Pero la impresión óptica nunca le bastó; de la tradición clásica tomó el rigor de la estructura, la lógica de la organización, el anhelo de universalidad. Lo que Cézanne buscaba producir con su pintura era el efecto, el tipo de serena conmoción que el orden clásico produce. Esto no quiere decir que supusiera en la naturaleza una verdad por descubrir. Tampoco que la hubiera en las ideas preconcebidas que pudieran aplicarse sobre ella, razón por la cual desestimó cualquier forma de idealización. La verdad que le interesaba era la verdad en pintura, como bien le expresara en 1904 a Bernard; una verdad que debe ser creada y realizada por y en la pintura. Precisamente en esto, la suya se distingue de las maneras tradicionales de comprender el clasicismo. 
Maurice Denis, un convencido clasicista que provenía de la tradición de Ingres, fue el responsable de instalar la noción de "clasicismo cezanniano". De Ingres derivaba también su admiración por Poussin y, junto con ello, la idea de que todo gran arte debe contar con una doctrina que lo avale. En efecto, según recuerdos de su discípulo Jannot, fue Ingres quien afirmó que su ideal era "rehacer lo antiguo por el estudio de la naturaleza”, frase que aparece después adaptada a Cézanne. En 1898, antes de conocer al maestro personalmente, Denis estaba convencido de que Cézanne era el modelo ejemplar capaz de salvar a la pintura del sensualismo informe del impresionismo ${ }^{2}$. A diferencia de los "taquígrafos impresionistas", Cézanne sometía la naturaleza a un análisis; sus obras "llevaban los rastros de un oficio paciente, aplicado" (Denis 307). Como destaca Reff, Denis identifica a Poussin con una tradición (francesa) de disciplina y orden "a la cual el arte moderno debe retornar y, encuentra en Cézanne al modelo de esa dirección que debe ser tomada” (Reff 162). Según Denis, el arte de Cézanne se define, en primer lugar, contra el impresionismo, pero no solo como oposición sino como alternativa, como salvación. Él logra esa salvación porque busca la perfecta síntesis entre naturaleza y estilo.

Denis se consideraba a sí mismo -y a Cézanne, por extensión- como un neotradicionalista, un clásico que no se dejaba dominar por las sensaciones sino que las empleaba con un método. Fue él quien lo instituyó como el "Poussin de los impresionistas" (313), el representante de una nueva forma de clasicismo. En su opinión, un cierto orden, obtenido mediante la síntesis que gobierna sus cuadros, permitía reunirlo con los viejos maestros. Era cierto que había abandonado las antiguas convenciones, lo que lo incluiría entre los reformadores impresionistas; con todo, contrastada su obra con las pinturas de Monet, Renoir o Pisarro, "los cuadros de Cézanne parecen obras de otra época, igualmente refinadas pero más robustas que las más fuertes producciones de la escuela impresionista" (301). Cézanne, agrega, "precipita los elementos efímeros accesorios y de pura sensibilidad del arte moderno (impresionista) y transforma en armoniosas y durable fórmulas los de aquellos elementos que satisfacen las afinidades clásicas" (303). Así describe su modalidad de trabajo:

Y por ejemplo en lugar de anotación cromática de los fenómenos, pudo conservar su emoción del instante, aún fatigado hasta el exceso, con un trabajo calculado y voluntario, sus estudios del natural. Compuso sus naturalezas muertas, variando de propósito las líneas y las masas, disponiendo los drapeados según un ritmo premeditado, evitando los accidentes de la casualidad, buscando la belleza plástica, pero sin perder nada del verdadero motivo; de ese motivo inicial que se sorprende desnudo en sus esbozos y acuarelas, quiero decir esa delicada armonía de matices yuxtapuestos que su mirada descubría primero, pero que

2 En sus palabras: "El arte ya no es más que el diario de la vida. El periodismo en pintura [...] la voluntad no resiste a los caprichos de una mirada demasiado sutil, el juicio no tiene lugar aquí, es el ojo el que sustituye al cerebro. Esta especie de taquigrafía ha deformado nuestra pintura” (Denis 82). 
su razón venía de inmediato a apoyar sobre la base lógica de una composición de un plan, de una arquitectura (303).

De acuerdo a Denis, la premeditación en el trabajo de Cézanne, esa rigurosidad en busca de una arquitectura del cuadro, marca definitivamente su distancia respecto de las ambiciones del impresionismo. Sin embargo, repara Denis, Cézanne se separa también de la dependencia realista del impresionismo, de su sometimiento irrestricto al mundo de las apariencias, para aventurarse en la realización del cuadro entendido como objeto independiente, autárquico. De ahí que compare a Cézanne con un pintor tan distinto a él como Odilon Redon:

Los temas de Redon son más subjetivos; los de Cézanne más objetivos, pero los dos se expresan a favor de un método que tiene por objetivo el de crear un objeto concreto, bello a la vez que representativo de una sensibilidad. El artista complejo como su época, que intentamos explicar, encontró pues en ese método su equilibrio, la unidad profunda de sus esfuerzos, la solución de sus antinomias. Emocionante es el espectáculo de una tela de Cézanne, muy a menudo, inacabada, raspada a cuchillo, recargada de falsos trazados, repintada varias veces, empastada hasta el relieve. En esa labor se advierte la lucha por el estilo y la pasión por el natural (307).

La obra de Cézanne puede parecer inacabada, "raspada a cuchillo", pero nunca va a ser simplemente abocetada como la de los impresionistas (a los que Denis generaliza sin piedad) porque está construida sólidamente sobre la base del equilibrio entre pasión y estilo. Como señala Denis, Cézanne era un pintor que buscaba solucionar las antinomias, resolver equilibradamente las sensaciones provocadas por el motivo con la organización compositiva. El clasicismo de Cézanne, si aceptamos el término, es un clasicismo nuevo justamente porque opera desde el natural, porque representa el compromiso entre lo aprendido y elaborado por la mente y lo registrado y experimentado por el ojo. La conjunción de ambos es lo que debe apreciarse en el cuadro como realización: la organización pictórica de aquello que experimenta el pintor en la forma de sensación. Aun cuando se distingue del impresionismo, el objetivo de Cézanne no era -como querían Bernard y Denis- negarlo, sino transformarlo: pretendía registrar con la sensibilidad los fenómenos para combinarlos justamente con el estilo.

Como Bernard, Denis también conoció a Monsieur Cézanne después de haberse familiarizado con su obra y su reputación. No obstante, su mirada es más penetrante y su juicio más sutil que el de Bernard. No atribuye los logros de Cézanne a una voluntad místico-racionalizante, sino que es muy perspicaz en notar la importancia que para la pintura cezanniana comporta aquello que el pintor experimenta frente a la naturaleza, lo que Cézanne llamaba la sensación. Denis entendió la condición colaborativa que opera entre el ojo y la mente, y a ella atribuye el peculiar clasicismo de Cézanne. El carácter clásico -y aquí clásico quiere decir armónico-, comprende 
Denis, es obtenido "espontáneamente", esto es, al margen de las normas académicas, en el mismo curso de la sensación. De acuerdo a Denis, la pintura de "tipo simbolista" de Cézanne realizaba dos clases de deformaciones. Una subjetiva, asociada a la expresión del temperamento del artista, y otra objetiva, más afín al estilo clásico, expresión de lo racional. La deformación, la cualidad desmañada de sus cuadros -aquello que lo revela como alejado de las convenciones de la representación pictórica- es para Denis manifestación de sinceridad y originalidad. En el caso de la pintura de Cézanne, ambas deformaciones se hallaban estrechamente ligadas, justamente porque es en la sensación que se conjugan lo percibido y el propio temple. Así, la naturaleza no es algo que se pueda percibir como pura exterioridad.

$\mathrm{Ni}$ al copiar la fisonomía ni los modelos de la tradición es que se consigue crear un efecto estético, una síntesis: la realización. El arte de Cézanne es, para Denis, un arte expresivo (que llega a la realización) porque logra representar no al mundo ni a nosotros mismos únicamente, sino las equivalencias entre ambos. Porque ha logrado sustituir la reproducción (reproduire) por la representación (représenter). La sensación se revelaba a través de equivalentes coloreados y solo de ese modo alcanzaba la realización:

El aparente desorden, las extrañas perspectivas que presenta un aparador pintado por Cézanne, tienden a situar el tema del cuadro en el centro de la composición, la armonía necesaria que busca ahí Cézanne: una armonía basada en los contrastes, la ley esencial del color, el respeto por el material, el amor a la claridad y la precisión y, por último, el carácter del sentimiento humano que sustenta y que crea la obra de arte. [...] No buscamos el motivo (fuerza motivadora y diseño resultante) de la obra de arte más que en la intuición personal, la percepción espontánea de una correspondencia, de un equivalente entre los estados mentales y los signos plásticos que deben traducirlos necesariamente (270).

"El sol es una cosa que no se puede reproducir; pero que se puede representar", habría dicho Cézanne en una de sus caminatas por las callejuelas de Aix, junto a Denis, quien recordaba:

él nos mostraba tan pronto el brillo hirviente del arroyo, incoloro vehículo de briznas luminosas, tan pronto las fachadas de las casas y los techos rutilantes de sol. Admirable fórmula que resumía en el contraste de estas dos palabras: "reproducir" y "representar", nuestra doctrina del simbolismo pictórico, no literario -el simbolismo de los "equivalentes"- opuesto al vano esfuerzo de la copia directa de los fotógrafos de la escuela de Bellas Artes y de los naturalistas de la escuela del "Temperamento" (271).

En otras palabras, no es la representación sino la reproducción mecánica lo que se debe abolir, y eso se alcanza poniendo atención a la sensación, traduciéndola con colores y con formas. "Yo he querido copiar la naturaleza -decía Cézanne-, no lo he conseguido. Pero me he sentido contento de mí cuando he descubierto que el sol, por ejemplo, no 
se puede reproducir, sino que hace falta representarlo por alguna otra cosa... por el color" (Cézanne cit. en Denis 306). De acuerdo a Denis, la técnica o los métodos que Cézanne ponía en práctica no tenían el solo objetivo de lograr un fin preconcebido, sino que constituían la realización artística misma. Esto suponía, por lo tanto, que cada cuadro ostentaba un valor propio y constituía un universo en sí mismo, una “realidad nueva", que en tanto tal no necesitaba ningún correlato en el mundo real:

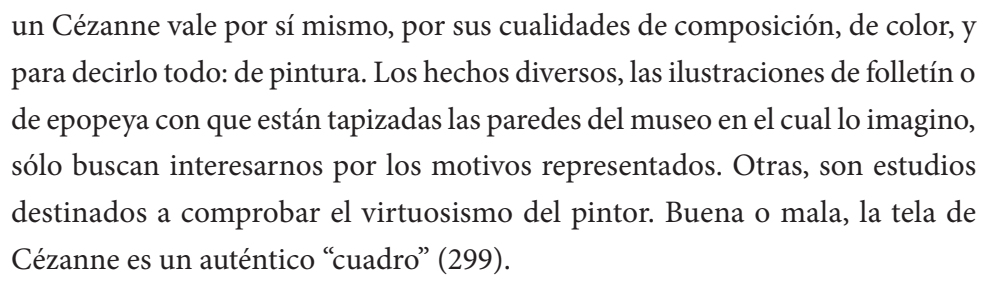

La pintura de Cézanne, continuaba Denis, "oscila eternamente entre la invención y la imitación" (304). Representa la posibilidad cierta de que la pintura se establezca como construcción de un mundo otro, una "armonía paralela". Frente a uno de sus cuadros, cualquier espectador de fines del siglo XIX o principios del xx podía notar que se trataba de una representación apartada de lo convencional, independientemente de si lo juzgara como logro, como fracaso o como enigma. La distorsión era entonces (y es aún) evidente, ya que "imita los objetos sin ninguna exactitud y no trata de interesarnos por ningún motivo accesorio de pensamiento o de sentimiento" (304). De ese modo, logra configurar la existencia plena y autosuficiente del cuadro, ejerce una verdadera poiesis. Para Denis, la pintura de Cézanne, clásica y renovadora, es el ejemplo más grande al que las nuevas generaciones animadas "por el retorno a la tradición" (321) pueden remitirse.

La interpretación simbolista prescinde de considerar que sus cuadros son el resultado de una atenta observación del mundo y prefiere suponer que son el resultado del esfuerzo imaginativo del pintor. Fue, en efecto, muy tentador para los artistas de Pont Aven y los Nabis suponer que Cézanne estaba, como ellos mismos, aplicando a su pintura los criterios simbolistas. Recordemos además que Cézanne llevaba la vida de un anacoreta, alejado de la urbe, consagrado plenamente a su pintura, apartado de éxito mundano, ocupado en nada más que su oficio; todo lo cual incitaba la generación de una leyenda. El aspecto de sus pinturas y su opción por el retiro fomentaron la inscripción de Cézanne en el marco simbolista.

\section{Conservadurismo y transformación}

Todo este marco teórico simbolista con el que sus primeros visitantes e intérpretes enfrentaron al maestro estaba contenido en esa especie de revolución conservadora que se ubicó en el último decenio del siglo xix. Escribo "conservadora" porque estaba animada por la vuelta a lo primitivo, a los orígenes; un "neotradicionalismo", en 
palabras de Denis. Orígenes que tienen que ver con la voluntad de mesura, de orden, de síntesis de lo primordial: un retorno a cierto ideal apolíneo. Lo primitivo era para los simbolistas identificado con el arte del primer renacimiento, el de los primitivos flamencos, el arte bizantino y el arte "decorativo" de la cultura egipcia o asiria. Lo que se aprecia de esas formas es la rigurosidad organizativa que ven reproducirse, por lo demás, en el arte del clasicismo barroco.

Para los fundadores de la modernidad artística, como Cézanne, ser primitivo habría significado remar contra la corriente de la incipiente modernidad industrial, urbana y social que encontraba en el impresionismo (la pintura "moderna") su correlato. Para la generación de 1890, ser primitivo era reinstaurar el orden perdido por aquellas tendencias que se habían limitado a seguir el modelo de la naturaleza. Por lo tanto, un arte original, un arte nuevo tenía que liberarse de esos imperativos, y para ello debía revivir una suerte de estado primitivo, naif (como había expresado de alguna manera Baudelaire años atrás), y esencial. Para el simbolismo, sin embargo, a diferencia de lo que pensaba Baudelaire, el arte debía reconciliarse con lo verdadero, lo trascendente y lo universal.

Denis bautizó a Cézanne como "el primitivo de un nuevo arte" (297). Serlo implicaba estar dispuesto a encontrar los fundamentos, a desestimar los prejuicios académicos, a encontrar el equilibrio entre naturaleza y estilo. Alejado tanto de las orientaciones académicas como de las naturalistas, que poblaron su siglo, Cézanne entendió, como antes lo hiciera Poussin, la necesidad de restituir dicho equilibrio: "el gran error de las academias del siglo xIx, es haber enseñado la antinomia entre el estilo y la naturaleza. Los Maestros no separaron jamás la realidad, en tanto que elemento de arte, de la interpretación de esa realidad" (Denis 329). En este sentido, era necesario recuperar el primitivismo para volver a instaurar nuevamente un orden clásico, pues la belleza estaba amenazada por una visión positivista, utilitaria y engañosa del mundo. Al imponerse la imitación de la naturaleza por el arte, las leyes eternas de la belleza se habían perdido; en consecuencia, la pintura había cedido a unos objetivos mecánicos y se desconsideraba la aprehensión del natural como clave interpretativa.

\section{Epílogo}

La gran meta de Cézanne, la realización, era hacer del arte "una armonía paralela a la naturaleza" (Cézanne 329). Ello solo podía lograse, pensaba él, a partir de la naturaleza. Únicamente el contacto del pintor con la naturaleza ofrece las sensaciones que luego son realizadas en el lienzo. Sin embargo, y a pesar de sus grandes dudas, Cézanne fue tan exitoso en alcanzar una "armonía paralela" con su pintura que esta misma devino un sustituto pleno de la naturaleza. De ese modo, los artistas cesaron de observar el modelo natural para atender al modelo de Cézanne en su lugar. La paradoja fundamental es que la asignación de ese lugar inaugural se fundamenta en la 
tesis según la cual la pintura moderna se constituiría como tal gracias al abandono de la mímesis y consecuentemente, del modelo, al contrario de lo que pensaba Cézanne. Esta tesis está determinada por la convicción de que la pintura moderna encarna la renuncia al modelo sensible y desdeña la reproducción de las apariencias. Por su peculiar fisonomía, la pintura de Cézanne se mostraba disponible para ser interpretada como un hito que marcaba el cambio de rumbo de la pintura: se ofrecía para ser leída como una pintura que le daba la espalda a la naturaleza. Todo lo cual, por supuesto, no coincidía en realidad con los intereses cezannianos. La cuestión entonces era preguntarse: ¿cómo un pintor que se apoya tan decididamente en el modelo natural puede convertirse en paradigma de una pintura que se define por su renuncia a él?

La realización del modelo fue para Cézanne la ardua tarea de su vida. Para el autor, el modelo estaba constituido por las sensaciones obtenidas frente al natural. Para los que leyeron o difundieron su obra ${ }^{3}$, el mismo pintor -o su pintura, mejor dicho-, fue modelo para la construcción de la cadena de intenciones y acontecimientos que articularon la tradición de Cézanne. Como se vio, el lugar paradigmático otorgado al pintor de Aix fue una elaboración del simbolismo rubricada por el formalismo anglosajón. En ambos casos, el empeño estaba puesto en la configuración de un modelo de pintura pura, como la música, como la poesía pura; una pintura de superficie, cuya opacidad representaba la superación de la transparencia del modelo renacentista del cuadro-ventana. Esta orientación que parte del esteticismo finisecular aportó el modelo a partir del cual se articuló, a su vez, un modelo de comprensión no solo de la obra de Cézanne, sino de la pintura y del arte moderno en general.

\section{Referencias}

Aurier, Albert. "El simbolismo en pintura: Paul Gauguin". Teorías del arte contemporáneo. Herschel B. Chipp. Madrid: Akal, 1995 [1891]. 105-109. Impreso.

Bell, Clive. Art C. S. Londres: BiblioBazaar, 2008. Impreso.

Bernard, Émile. "Paul Cézanne". Conversaciones con Cézanne. Ed. Michael Doran. Barcelona: Gustavo Gili, 1980. 55-70. Impreso.

---. "Recuerdos sobre Paul Cézanne". Sobre Cézanne: conversaciones y testimonios. Michael Doran. Barcelona: Gustavo Gili, 1980 [1907]. 78-116. Impreso.

---. “Una conversación con Paul Cézanne” Sobre Cézanne: conversaciones y testimonios. Michael Doran. Barcelona: Gustavo Gili, 1980 [1921]. 214-217. Impreso.

Bozal, Valeriano. Los primeros diez años: 1900-1910, los orígenes del arte contemporáneo. Madrid: Visor, 1993. Impreso.

3 Labor que fue seguida en Inglaterra principalmente por el pintor y crítico Roger Fry, quién se encargó de traducir a Denis al inglés además de acuñar el término "postimpresionistas" para referirse a la obra de Cézanne y sus contemporáneos Van Gogh y Gauguin, entre otros. 
Cézanne, Paul. Correspondance. Ed. John Rewald. París: Bernard Grasset Editeur, 1937. Impreso.

---. Correspondencia. Ed. John Rewald. Madrid: Visor, 1991. Impreso.

Chipp, Herschel. Teorías del arte contemporáneo. España: Akal, 1995. Impreso.

Denis, Maurice. Teorías. Buenos Aires: Ateneo, 1944. Impreso.

Doran, Michael. Sobre Cézanne: conversaciones y testimonios. Barcelona: Gustavo Gili, 1980. Impreso.

D'ors, Eugenio. Cézanne. Barcelona: El acantilado, 1999. Impreso.

Jenny, Laurent. El fin de la interioridad: Teoría de la expresión e intención estética en las vanguardias francesas (1885-1935). Madrid: Cátedra, 2003. Impreso.

Reff, Theodore. "Cézanne and Poussin". Journal of Warburg and Courtauld Institute 23 (1960): 150-174. Impreso.

Rilke, Rainer Maria. Cartas sobre Cézanne. Trad. Nicanor Ancoechea. Buenos Aires: Paidós, 2000. Impreso.

Shiff, Richard. Cézanne y el fin del impresionismo: estudio de la teoría, la técnica y la valoración crítica del arte moderno. Madrid: Visor. 2002. Impreso.

Solana, Guillermo, ed. El impresionismo: la visión original. Antología de la crítica de arte (1867-1895). Madrid: Siruela, 1997. Impreso.

Todó, Lluis María. El simbolismo: el nacimiento de la poesía moderna. Barcelona: Montesinos, 1987. Impreso.

Recibido: 10 octubre 2015

Aceptado: 5 septiembre 2016 